\title{
Young Minds: Mental Health and Transitional Care in Adolescent and Young Adult Rheumatology
}

This article was published in the following Dove Press journal:

Open Access Rheumatology: Research and Reviews

\author{
Jason Palman (iD) \\ Janet E McDonagh (D) ${ }^{1-3}$ \\ 'Department of Paediatric and \\ Adolescent Rheumatology, Royal \\ Manchester Children's Hospital, \\ Manchester University Hospitals NHS \\ Trust, Manchester MI3 9WL, UK; \\ ${ }^{2}$ Versus Arthritis Centre for \\ Epidemiology; Centre for MSK Research, \\ University of Manchester, Manchester, \\ UK; ${ }^{3} \mathrm{NIHR}$ Biomedical Research Centre, \\ Manchester University Hospital NHS \\ Trust, Manchester, UK
}

\begin{abstract}
Consideration of the mental health and emotional wellbeing is an important component of health care for all young people, irrespective of setting. Mental health disorders are common during adolescence and young adulthood and young people with rheumatic musculoskeletal diseases (RMD) are not exempt. For such young people, risks of poor outcomes are related to both mental health as well as their RMD. Times of change during adolescence and young adulthood - transitions - are potentially vulnerable life stages for young people with RMD and warrant specific attention in health care provision. Such transitions include those occurring at puberty, during education, training, and employment, socially with moves away from the parental home, as well as from child to adult-centered health services. There is great potential for rheumatology professionals to support young people with RMD at these transitions in view of their frequent encounters and ongoing therapeutic relationships. In this review, we aim to assess the impact of mental health on RMD during adolescence and young adulthood with particular reference to transitional care provision and how rheumatology professionals can be involved in addressing mental health issues during this time of change.
\end{abstract}

Keywords: adolescent, young adult, developmentally appropriate health care, transitional care, rheumatology, rheumatic musculoskeletal disease, mental health

\section{Introduction}

Mental health disorders are common during adolescence and young adulthood. Fifty percent of all lifetime mental health disorders (classified by DSM-IV) have an onset by 14 years, and $75 \%$ by 24 years of age. ${ }^{1}$

In the UK, $14.4 \%$ of $11-16$ year olds and $16.9 \%$ of $17-19$ year olds met the criteria for having a mental health disorder ${ }^{2}$ with a trend for these disorders to increase in the early teens for both genders, and then to continue increasing into the late teens for young women. There is increasing concern that rates of emotional disorder are rising across the developed world. ${ }^{3,4}$ At the time of writing there is an additional concern of the impact of the COVID-19 pandemic on the emotional wellbeing of young people. ${ }^{5}$

Young people with chronic disease (including rheumatic musculoskeletal disease, RMD) ${ }^{6,7}$ have been reported to be more likely to have mental health disorders than healthy individuals, with some authors reporting up to a fourfold risk. ${ }^{8-12}$ In certain RMDs, such as systemic lupus erythematosus (SLE), there are direct effects on the brain and nervous system caused by the condition itself resulting in additional psychological morbidity. ${ }^{13}$

Risks for poor outcomes in RMD conditions are often found to be related to both mental health status as well as their RMD. For example, in juvenile idiopathic arthritis (JIA), young people who experience symptoms of depression and anxiety
Correspondence: Janet E McDonagh Centre for MSK Research, University of Manchester, Stopford Building, 2nd Floor, Oxford Road, Manchester MI3 9PT UK Tel +44 I6I 2751670

Email janet.mcdonagh@manchester.ac.uk
Open Access Rheumatology: Research and Reviews 2020:12 309-32I in $\mathbf{P}$ 
have worse quality of life and furthermore these symptoms may have a greater impact on quality of life than the actual disease activity itself. ${ }^{14}$

During adolescence and young adulthood there are many transitions taking place whether they be biological in terms of puberty, social (development of intimate relationships, leaving the parental home), educational and vocational (moving schools, moving to university, starting the first job) as well as health transitions when young people move from child-centered to adult centered health services. Transitional care in health addresses the medical as well as the psychological, social, and educational/vocational issues as the young person moves from pediatric to adult health care. ${ }^{15}$ There are now international recommendations available for how such care should be provided $^{16}$ which state that it should be developmentally appropriate. $^{17}$

Rheumatology professionals are well placed both to identify and address mental health issues during adolescence and young adulthood in view of the frequent encounters and ongoing therapeutic relationships. This is particularly pertinent at the aforementioned transitions when, if the young person is ill-prepared for the changes these life stages bring, they can also become times of crisis. In this review we aim to assess the impact of mental health on RMD during adolescence with particular reference to transitional care provision and how rheumatology professionals can be involved in addressing mental health issues during this time of change. We searched the PubMed database for all full English language publications from the last 15 years (until June 2020) using search terms related to juvenile RMDs, adolescents, transitional care and mental health (depression and anxiety). Although there is a breadth of literature on mental health in juvenile RMD, there is less literature focussed on mental health during the health transition process.

\section{Mental Health and RMD}

Current literature on the prevalence and incidence of psychological morbidity in young people with rheumatic diseases, is of variable quality and quantity and predominantly cross-sectional, rather than longitudinal and largely centered on JIA rather than the less common RMD. More research in this area has therefore been called for $^{18,19}$ but a brief summary of current evidence is presented below.

\section{JIA}

Evidence from qualitative literature involving children and young people (CYP), categorizes the impact of JIA into six themes, many of which could be described as psychological, ie aversion to being different, striving for normality, stigma and misunderstanding, suspicion in uncertainty, managing treatment, and desire for knowledge. ${ }^{20}$ Living with the unpredictability of relapsing and remitting conditions such as JIA can be particularly challenging for young people during adolescence. A systematic review considering the construct of illness uncertainty in young people including those with rheumatic conditions reported that illness uncertainty was associated with illness distress and poorer psychological functioning. ${ }^{21}$

Anxiety and depression in JIA has been studied in a comprehensive systematic review of 60 articles (28 articles within last 10 years). ${ }^{14}$ Studies using validated screens for depressive or anxiety symptoms reported prevalence of clinically significant symptoms in the range of $7-36 \%$ and $7-64 \%$, respectively. ${ }^{14}$ Most studies reported worse depressive and anxiety in young people with JIA than healthy controls although a recent study reported no difference. ${ }^{22}$ When compared to primary immunodeficiencies, CYP with JIA had similar rates of mood disorders; however, CYP with inflammatory bowel disease and cancer reported higher rates of depressive symptoms. ${ }^{23-25}$

When considering the individual JIA subtypes, some studies have reported differences between subtypes, eg young people with polyarticular disease scored significantly higher than oligoarticular and enthesitis related subtypes on depressive symptoms ${ }^{26}$ whereas in others no such differences were found. ${ }^{27}$

Many authors have reported a correlation between disease activity markers and depressive symptoms although not sustained over time $\mathrm{e}^{26-28}$ and some studies failed to show such relationships. ${ }^{22,29}$

Hanns et al reported that in adolescents with JIA, anxiety and depressive symptoms were associated with pain, disability, and physician global assessment VAS, but not with markers of inflammation. ${ }^{22}$

Similar variation has been reported with disease outcomes. Several authors have reported a significant relationship between functional disability (as measured by the Childhood Health Assessment Questionnaire) and depression scores. ${ }^{26-29}$ 


\section{SLE and Vasculitides}

As with JIA, SLE can be challenging during childhood and adolescence. In one study, young people with SLE (aged 11-22 years) reported the key aspects of living with SLE to include: stigma, Illness uncertainty, psychological coping as well as managing disease and limitations which result. ${ }^{30}$ In another study involving young people with SLE, parents' illness uncertainty regarding their child's condition correlated to the child's illness uncertainty, which then was associated with the child's mental health and wellbeing. ${ }^{31}$ It therefore is important for rheumatology professionals to proactively acknowledge and address this uncertainty with both young people and their parents in routine clinical practice.

Objective neuropsychiatric manifestations of SLE such as stroke, seizures, or transverse myelitis are relatively easy to recognize clinically unlike the more subjective presentations of headache, cognitive impairment and mood disorders particularly when depression in this age group is not rare, with a reported prevalence of approximately $5 \%$ in early adolescence and $20 \%$ by late adolescence. ${ }^{32}$ Research is ongoing for reliable noninvasive biomarkers in this age group to determine whether anxiety and depression is specifically related to disease activity. ${ }^{33}$

A systematic review by Quilter et al reported the prevalence of depressive symptoms in childhood onset SLE to be $6.7-59 \%$ and anxiety $34-37 \% .{ }^{13}$ In conditions such as SLE or other systemic vasculitides, as well as potential direct effects on the brain and nervous system caused by the condition itself, the impact of receiving a diagnosis such as these conditions and coming to terms with it, the relative rarity of the conditions, their potential severity, uncertainty of outcome and significant side effects of necessary drug therapy may all contribute to mental health in such young people. Young people (mean age 16.1 years) with SLE were found to have lower health related quality of life, with fatigue, pain, low mood, and anxiety as contributors to this. ${ }^{34}$

Younger adults with SLE (18-45), particularly those with juvenile-onset disease, ie diagnosed under the age of 18 years, are at high risk for major depression, which is associated with increased disease activity, poorer physical functioning, and lower educational attainment. ${ }^{35}$ Early depression intervention in young adults with SLE has the potential to improve both medical and psychosocial outcomes.
In a qualitative study exploring the illness experience of young people with SLE ( $\mathrm{n}=16$ ), four reported adapting less well to the condition. The latter young people were experiencing challenges in more than one area and had lower psychological function, were older, of lower socioeconomic status and had increased disease-related morbidity. They also reported suboptimal treatment adherence, health-care utilization and transition to adult care ${ }^{30}$ all potentially modifiable factors and core to any transitional care program.

\section{Chronic Musculoskeletal Pain Syndromes}

A major component of pediatric and adolescent rheumatology practice are young people with chronic idiopathic musculoskeletal pain. AYA with chronic pain report that they are less socially developed on virtually every metric than their peers. ${ }^{36}$ The absence of inflammation or structural abnormality as the cause of the pain is often perceived by the young person and/or the family as diagnostic uncertainty which, as mentioned, is challenging to learn to live with. ${ }^{37,38}$

There is a strong and reciprocating relationship between anxiety and pain with over $80 \%$ of CYP with chronic pain meeting the criteria for an anxiety disorder. ${ }^{39}$ Jastrowski Mano et al have proposed a developmentally informed shared vulnerability model to inform future research. This model postulates that young people at increased risk for the development of chronic pain and/or anxiety share predisposing vulnerabilities. These shared vulnerabilities then give rise to negative emotional responses (both in child and parent) in the context of stressful events. Consequences of fear and anxiety, including avoidance behavior, further contribute to the development of chronic pain, anxiety, and their co-occurrence. ${ }^{39}$

Current evidence supports the mainstay of management for such young people with a young person centered rehabilitation and pain management program involving psychology (often devised around a cognitive behavioral therapeutic model) as well as physiotherapy and occupational therapy. ${ }^{40}$ For further discussion of this area, see Soltani et al. ${ }^{41}$

\section{Specific Anxiety Inducing Procedures}

Many RMD carry with them a burden related to managing the disease in terms of medications and blood test monitoring. In an observational study of CYP with JIA, methotrexate-induced nausea was associated with anxiety and the use of coping strategies. The authors proposed that 
psychological factors may therefore be part of the mechanism behind the inter-individual variation in the level of nausea to methotrexate treatment. ${ }^{42}$ In another study of parents of 230 CYP with JIA on methotrexate for at least six months, fear of injections and/or blood tests rated as often or almost always was reported in over a third of CYP with over half reported as experiencing them at least sometimes. Anxiety related to blood tests was an independent predictor for poorer scores in the psychosocial scales of quality of life. ${ }^{43}$ Intra-articular joint injections are another source of procedural pain particularly when done without general anesthetic. This is a particular challenge for young people transferring to adult rheumatology care when all such injections will be done when awake with only topical anesthetic. A potential compromise to support this gradual transition is reported by Elitsur et $\mathrm{al}^{44}$ who reported that their minimal sedation/anxiolysis protocol (including nitrous oxide, intranasal fentanyl, a topical numbing agent, acetaminophen, ibuprofen, ondansetron and play therapy), provided safe and effective analgesia for intra-articular corticosteroid injection in a subset of CYP with JIA and offered a lower cost alternative to general anesthesia. It is important to note that doctors and nurses often underestimate procedural pain. ${ }^{45}$

It is also important not to make assumptions that all would choose anesthesia if given the choice. In one Spanish study 15 of 45 young people preferred without and gave reasons including quickness, fear of sedation, pre-sedation dizziness. Four did not express a preference. ${ }^{46}$ In another study addressing injection training for subcutaneous drug administration, Sorenson et al reported that it was important for professionals and parents to use acknowledging communication styles with CYP and to offer sufficient coping strategies. The initial training session may have a great impact on long-term repeated injections by providing CYP with confidence from the outset. ${ }^{47}$ Finally, addressing both child and parental anxieties about painful procedures is just as important as adequate analgesia.

\section{Mental Health Within the Family}

Parenting a child with a long-term health condition like JIA or SLE is challenging. ${ }^{48}$ In their systematic review, Fair et al reported that there were high rates of anxiety and depression symptoms within family members of young people with JIA, which in turn may impact upon the mental health of the young people themselves. ${ }^{14}$ In an allage study of people with SLE (age range 12-73), associations were found between their quality of life and psychological status and that of their relatives. ${ }^{49}$ In another large study of CYP with a range of chronic conditions including JIA, parents, especially mothers, reported high levels of anxiety and depression. ${ }^{50}$ It therefore is important that mental health of the family is routinely considered in the assessment and management of young people with RMD.

\section{Mental Health Outcomes in Adulthood}

Outcomes for childhood-onset RMD have improved significantly in recent years since the advent of biologics. However, although disease activity measures improved at 15-30 years of follow-up, patient-reported outcomes in JIA including global well-being, quality of life, and functional ability scores did not. ${ }^{51}$ Greater understanding of this disconnect is needed. Research into psychological outcomes across both inflammatory and noninflammatory RMD will help to explore which mechanisms are specific to inflammatory processes as well as those associated with the symptoms common to all RMD, eg pain, fatigue.

In recent years, adults with childhood onset RMD have been increasingly recognized rather than becoming lost within the larger populations of adult onset RMD. Of three such studies, ${ }^{28,52,53}$ two reported a high prevalence of either depression or anxiety symptoms in adults with JIA. $^{28,53}$ In contrast, Raab reported significantly fewer adults with JIA reporting depressive symptoms compared to the general population. ${ }^{52}$

In young adults with SLE the prevalence of depression has been estimated to be $47 \%$ and after adjusting for age of onset, young adults with juvenile-onset SLE had higher risk of a major and recurrent depressive episodes odds ratio $1.7(95 \% \mathrm{CI}: 1.0-2.7)$ and $2.2(95 \% \mathrm{CI}: 1.2-4.3)$ respectively compared to adult-onset SLE. ${ }^{35}$ In multiple adult studies, patients with SLE had higher prevalence of major depression, severe anxiety and emotional distress. ${ }^{54,55}$ Overall meta-analysis of depression and anxiety in SLE was reported at $24 \%$ and $37 \%$, respectively. ${ }^{56}$ These studies show the high prevalence and associated mental health in SLE-related to disease activity and burden, aesthetics associated with medication and the disease's stigma and highlights the need for early mental health intervention. ${ }^{57}$

Work remains to ensure that a life course to rheumatology research is advocated and prospective long-term research following young people with childhood and adolescent onset disease into adulthood is both prioritized and 
enabled including funding. This will require particular attention to the peritransfer period to ensure effective mechanisms to follow these often geographically mobile young people so that they are not lost to follow-up and that the information gained is disseminated to CYP and families still in pediatric care.

\section{Mental Health and Transition}

Transition from pediatric to adult-centered health care is a particularly vulnerable period for adolescents and young adults (AYA). A study investigating the effect of transition of 50 young people with SLE in the absence of a formal transition program found that SLEDAI scores remained moderate but stable, however depression and anxiety and SLICC scores increased post-transfer. ${ }^{58}$ The EULAR/ PReS standards for transitional care ${ }^{16}$ highlights the importance addressing psychological wellbeing during this life-stage in addition to the promotion of individual skills in self-care, self-determination, and self-advocacy. The latter skills have been reported to be associated with better transition outcomes. ${ }^{59}$ The EULAR standards ${ }^{16}$ also advocate the routine use of psychosocial screening tools during this time such as HEEADSSS, Home, Education, Eating, Activities, Drugs, Sex, Suicide and affect, safety, ${ }^{60}$ which explicitly includes trigger questions to assess mental health and emotional well-being.

The different personalities and backgrounds of young people will play an important role in the approach that they will take to the transition process. These have been reported to group into four categories, namely anxious, laid-back, autonomy-seeking, and socially orientated. ${ }^{61}$ In order to meet individual needs the clinician needs to adapt their therapeutic approach to parallel the young person. However, it is not yet known whether these categories remain consistent throughout the transition process, or change as the young person matures.

Psychological outcomes are rarely reported as a transition outcome $\mathrm{e}^{14}$ and the measuring of psychological outcomes in transitional research is seldom reported. A range of outcomes measures have been developed which assess the mental health of AYA. ${ }^{62}$ According to the authors the most common clinician-reported outcome in mental health is the Children's Global Assessment Scale. ${ }^{63,64}$ However, more composite scoring systems have been developed that contain CYP and parental indices and family functioning, with some of these scores being used as a routine clinical outcome measurement. The Strengths and Difficulties Questionnaire (SDQ) has been widely used to evaluate parent, carer, teacher, and patient reported outcome measures (PROM) ${ }^{64}$ This scoring system focusses on the 11-17-year age range. Using PROMs is more time effective for secondary care and gains an insight into broader domains of home, education and social life than clinician-reported outcome measures. Serial SDQ scores can be supplemented by the Health of the Nation Outcome Scales: Child and Adolescent Mental Health to combine the patient and clinician-reported outcome measures. ${ }^{65}$

There are a range of transition readiness tools available including both generic or disease specific measures. ${ }^{66}$ A rheumatology specific one has been reported in the early stages of development but like the others, did not include any specific mental health domains. ${ }^{67}$ Readiness tools were developed as part of a large multicenter transitional care program in rheumatology which did include psychological domains ${ }^{68}$ and have since been both used by some ${ }^{69}$ and adopted in a generic format by others,${ }^{70}$ but these have not been validated.

The most widely used validated scoring system is the Transition Readiness Assessment Questionnaire (TRAQ) designed as a generic tool to aid clinicians in assessing the transition readiness of older adolescents and young adults (16-26 years). ${ }^{71}$ Unfortunately, the scoring system has not been validated in younger adolescents (12-16 years) which shows the importance of developmentally appropriate outcome measures, and different developmental challenges that are faced during transition. ${ }^{72}$ One could argue that many of the measures available are transfer rather than transition readiness tools focussing on the older adolescent rather than the more dynamic lengthy process of transition which starts in early adolescence. A more detailed score that has content validity across a wider age range (12-22 years) is the UNC TRxANSITION score uses 10 domains and the ability to cross-reference with medical history. ${ }^{73,74}$ However, the tool, like TRAQ, must be individually examined for external validity as the domain of health insurance will not be applicable to all health care systems.

It is surprising that in spite of the significant psychological issues reported in the qualitative literature which surrounds transition, ${ }^{75}$ that transitional readiness tools do not contain domains relating to mental health. A systematic review of barriers to transition only eluded to anxiety at the time of transition with the only mental health issue being the thought of terminating the relationship. ${ }^{76}$ Due to the paucity of research, the study 
could not evaluate transition for any mental health related conditions nor mental health factors that may obstruct transition. Emotional issues have been reported as a primary contributor to transition difficulties resulting in poor symptom control, ongoing and new organ involvement. ${ }^{77}$ The emotional experience of young people transferring to adult mental health services was reported to be characterized by the loss of relationships with clinicians and fear of less support in adult mental health services service. $^{78}$ It is therefore important to acknowledge the potential psychological impacts of the transition process itself and proactively address it in transitional care programs.

The system for transition from child and adolescent mental health services to the adult mental health service has been reported to inadequate compared to other health services. ${ }^{79-81}$ Research into transition tools for mental health is under way with the published protocol for the development and validation procedure of the "managing the link and strengthening transition from child to adult mental health care (MILESTONE)" suite of measures. ${ }^{81}$ How such tools will work at the interface between rheumatology and mental health services for those young people with RMD and a mental health comorbidity remains to be seen. Such young people will need a coordination of transition and transfer in order to be least disruptive to the management and ongoing care. Transfer at the point of a flare/relapse in either condition will increase the risk of a negative transfer and utilization of adult rheumatology services.

The transition from pediatric to adult services represents a fragile gap in health care. In both rheumatology and mental health there is a paucity of tools to support transition and transfer at the correct time. Poor judgement and inadequacies of the process are detrimental both to the individual and society. System level issues such as ensuring continuity of funding for drug therapies, eg biologics is an additional concern ${ }^{82}$ and specifically highlighted in the EULAR recommendations. ${ }^{16}$ Having rheumatic and mental health diseases is common, and therefore, robust interdisciplinary coordination of transition must be paramount to ensure a smooth transfer of care.

Another transition is that of the gradual transfer of responsibility for the management of both health and the RMD from the parent to the young person ${ }^{83}$ who becomes the manager of their own health and therapy. Suboptimal treatment adherence and health-care utilization has been reported by young people with SLE, which in turn was associated with reduced psychological functioning. ${ }^{30}$ Mental health and adherence have been reported to be closely linked. ${ }^{84}$ In a recent integrative review, Zheng et al highlighted that studies in JIA were limited but that depressive symptoms did affect hospitalization rates/costs. The evidence in the diabetes literature was stronger and increased depressive symptoms in adolescents with diabetes predicted decreased metabolic control and monitoring, medication adherence and increased hospitalizations as well as quality of life. ${ }^{85}$ Such evidence further supports the need for routine mental health assessment in rheumatology practice including when assessing adherence to medication, therapy and attendance at appointments, etc.

Transitions from primary to secondary education as well as the transition from statutory schooling to college/ training/university/employment is another vulnerable period for adolescents. There are distinct age-related changes in social development and risk-taking behaviors as the adolescent brain develops which have been mapped to anatomical and biomechanical adaptations of the adolescent brain, ${ }^{86,87}$ and in turn make such transitions challenging for all AYA, particularly so for those with mental health comorbidities. College students in the USA attributed $64 \%$ of mental health difficulties to nonattendance or withdrawal from college. Half of these students did not disclose a mental health condition, and more concerning, $73 \%$ had a reported crisis on campus. ${ }^{88}$ The increase in autonomy for attending clinic appointments, taking medication and use of other therapies during the school/ college day adds further pressures to adaptation to educational settings. A systematic review of nonadherence of psychotropic medication in AYA found an overall median of $33 \%$ (range: $6-62 \%$ ) not adhering to medication. ${ }^{89}$ Furthermore four studies found an association between nonadherence and an increase in substance misuse. ${ }^{89}$ Regular discussion of these issues during the transition period, remaining nonjudgemental and supportive, and highlighting the importance of getting further support from supervisors in education are useful measures clinicians can employ to minimize these risks.

A fundamental aspect of JIA is the chronicity of pain that has a significant impact on education and vocational development. CYP with chronic pain have a higher rate of absenteeism than other chronic health conditions. ${ }^{90}$ The most common clinical manifestations of anxiety among CYP with chronic pain include school phobia, separation anxiety and social anxiety. ${ }^{91}$ Specific school-related anxieties include the fear of academic failure, experiencing 
physical symptoms at school and negative peer evaluation. ${ }^{90}$ Unfortunately, comprehensively measuring the impact of the chronic pain and chronic disease on school anxiety has not been established. Understanding the duality of chronic pain and disease burden on school related anxiety is incredibly important in JIA as pain often persists after treatment of the inflammatory phase. ${ }^{92}$ Table 1 provides examples of important considerations for developmentally appropriate transitional care provision with specific reference to mental health

\section{Mental Health Strategies and Interventions in Rheumatology Settings}

A simple management strategy for all rheumatology professionals to adopt is to routinely introduce the concept of the psychological impact of all RMD at the time of diagnosis, irrespective of condition, for all young people and their families. Furthermore, discussing the impact of the condition on adolescent and young adult development is also important, emphasizing that one of the goals of management is to ensure developmental milestones are met and achieved whether they be biological, psychological, social, and/or vocational milestones.

In one study, young people with SLE and mixed connective tissue disease and their parents reported that pediatric rheumatologists were their preferred source for mental health screening, guidance and referral. ${ }^{93}$ In a CARRA survey exploring mental health in SLE, however, 52\% professional respondents reported inadequate identification of depression/anxiety while $77 \%$ felt routine mental screening should be conducted. ${ }^{94}$ Barriers and facilitators for such screening have been identified both from the patient and the professional perspective (Table 2). ${ }^{93-96}$ Interventions in this area potentially should aim to lift and/or remove these barriers while enhancing the facilitators and in so doing will potentially improve mental health care for young people with RMD.

Routine psychosocial screening tools such as HEEADSSS $^{60}$ are useful in this regard not only to engage young people, but also to identify both risk and protective factors. An App is now available as a useful aide memoire for trainees. ${ }^{97}$ The potential of tablet-based screening tools with young people with long-term physical conditions are awaited with interest as they can be used prior to the actual consultation and the information gained can then inform the consultation, eg YouthCHAT (Youth version, casefinding and help assessment tool) which is an electronic, psychosocial screener for young people, which has been shown to be acceptable and feasible to use with young people with long-term physical conditions. ${ }^{98}$

Involvement of the multidisciplinary team (MDT) is imperative for managing young people with overlapping medical and mental health conditions. However,

Table I Transitional Care and Mental Health of Young People

\begin{tabular}{|c|c|}
\hline $\begin{array}{l}\text { Area of Transitional } \\
\text { Care }\end{array}$ & $\begin{array}{l}\text { Examples of Important Considerations for Developmentally Appropriate Transitional Care Provision } \\
\text { with Specific Reference to Mental Health }\end{array}$ \\
\hline Organizational & $\begin{array}{l}\text { Coordination of care in peritransfer period to include mental health-care provision } \\
\text { Inclusion of mental health related knowledge and skills in transition readiness check lists to ensure regular assessment } \\
\text { Mental health training of rheumatology health professionals } \\
\text { Ideally, specific psychological expertise within the rheumatology team in both adolescent and adult services, eg psychologist }\end{array}$ \\
\hline Specific clinical issues & $\begin{array}{l}\text { Routine developmental assessment during adolescence to assess whether young people are predominantly concrete } \\
\text { thinkers or have developed abstract thought } \\
\text { Adherence to therapy-nonadherence may be associated with low mood, anxiety, etc so important to routinely address } \\
\text { in a nonjudgemental manner, eg when did you last forget to take your meds? } \\
\text { Consideration of impact of having serious medical illness, eg SLE, juvenile dermatomyositis, vasculitides-potentially life- } \\
\text { threatening } \\
\text { Consideration of biographical disruption and adjusting to life with a long-term health condition } \\
\text { Drug toxicity, eg depressed mood on corticosteroids } \\
\text { SLE-risk of neuropsychiatric disease which may present subtly as headache, cognitive impairment or mood disorder } \\
\text { Knowledge and skills in disclosure of condition to others } \\
\text { Body image-steroid-related side effects particularly during peripubertal stage; skin rashes; lipodystrophy and calcinosis } \\
\text { in juvenile dermatomyositis; localized growth impairment, eg limb length discrepancy in inflammatory arthritis; nasal } \\
\text { cartilage loss in granulomatosis with polyangiitis }\end{array}$ \\
\hline
\end{tabular}


Table 2 Barriers and Facilitators to Addressing Mental Health Care in Rheumatology Clinics

\begin{tabular}{|c|c|}
\hline Facilitators & Barriers \\
\hline Strong clinician relationships & Stigma \\
\hline Clinician initiative & Fear \\
\hline Sincerity and normalization in discussing mental health by clinicians & Uncertainty about getting help \\
\hline Increased patient/family awareness of mental health issues in RMD & Parental emotional burden \\
\hline Opportunity for young person to be seen independent of caregivers & Minimization by health professionals \\
\hline Enough time & Limited time \\
\hline $\begin{array}{l}\text { Assurance of confidentiality and how and when it would have to be } \\
\text { breached }\end{array}$ & Limited staff resources \\
\hline Routine psychosocial screening (eg HEEADSSS) & Lack of training of team members \\
\hline $\begin{array}{l}\text { Routinely introducing the concept of psychological impact at time of } \\
\text { diagnosis }\end{array}$ & Limited mental health care access including long waiting lists \\
\hline Involvement of the multidisciplinary team & $\begin{array}{l}\text { Limited knowledge of local resources which young people can be } \\
\text { signposted to }\end{array}$ \\
\hline
\end{tabular}

Note: Data from references ${ }^{61}$ and ${ }^{94,95,96,97}$.

psychological support for CYP with RMD in the UK is inadequate. ${ }^{99}$ This is not surprising with the huge variability of access to psychology and psychiatry within the National Health Service (NHS), long waiting lists and low doctor-patient ratios compared to other European countries. ${ }^{100,101}$ Tackling this problem may come through two means, either increasing the Child and Adolescent Mental Health Services, or by training the paediatric rheumatology MDT teams in supporting CYP with mental health. ${ }^{102}$ Davis et al outlines that CYP with chronic rheumatological diseases would feel comfortable speaking to their rheumatologist about mental health concerns, especially as most CYP view their rheumatologists as their primary doctor as opposed to their general practitioner. ${ }^{102}$ Currently most pediatric rheumatology MDTs are insufficiently prepared to straddle this dual responsibility. ${ }^{94}$ However, integrating mental health training, clinical guidelines and support from child and adolescent mental health services may be a favourable balance to the chronic shortage of mental health services for this age group.

The systematic review by Fair et al identified a paucity of longitudinal studies which considered the impact of therapeutic intervention on mental health in the context of a $\mathrm{RMD}^{14}$ echoing similar results of systematic reviews which considered long-term physical conditions. ${ }^{103,104}$ Thabrew et al concluded that according to current evidence, therapies specifically designed to treat health-related anxiety in this age group were limited and that therapies specifically designed to treat anxiety or depression, especially those based on principles of cognitive behavior therapy (CBT), may be more likely to work in young people with mild to moderate symptoms of these disorders, at least in the shortterm. ${ }^{104}$ Results from research such as is proposed with the tailored CBT protocol for young people with SLE to address fatigue and depressive symptoms by Cunningham et al are awaited with interest. ${ }^{105}$

\section{Workforce Competency and Service Level Issues}

Ensuring workforce competency to address mental health issues remains imperative for rheumatology services. Pediatricians have been reported to identify only $25 \%$ of CYP meeting criteria for emotional/behavioral disorders ${ }^{106}$ and family practitioners have been reported to have difficulty identifying mental health needs in CYP. ${ }^{107}$ In a recent survey of 166 health professionals (including rheumatology professionals) involved in the care of young people (11-24 year olds), only 37\% reported adequate knowledge and $35 \%$ skills to address mental health issues in this age group. ${ }^{96}$ The major barrier reported by trainees in adult medicine was training with respect to this age group and the second barrier was time ${ }^{108}$ echoing other studies, ${ }^{109,110}$ including two addressing care of young people with SLE. ${ }^{94,95}$ Attention is, therefore, needed with respect both to workforce competency in addressing mental health of young people with RMD and also how supportive the health-care system is to enable this to happen-how developmentally appropriate $^{111}$ and youth-friendly ${ }^{112}$ is it? Are young people offered the opportunity to be seen independent of the caregiver, are the consultation times allocated long enough to enable mental health issues to be addressed? There are 
Box I Key Messages

Significant Impact of RMD on Mental Health and Emotional Well-being

Key aspect of developmentally appropriate transitional care

Need to lift the existing barriers in routinely addressing mental health in rheumatology care settings

Adolescence and young adulthood have multiple transitions, one of which is health but all are potentially vulnerable times for AYA mental health

Mental health is an important health outcome for RMD as well as for transitional care

Significant need for more research in this area in the 10-24 year old age group

now useful tools available to evaluate such services, eg a benchmarking toolkit for adolescent and young adult rheumatology services. ${ }^{113}$

\section{Research Challenges and the Way Forward}

The Childhood Arthritis and Rheumatology Research Alliance (CARRA) Mental Health Workgroup proposed five broad priority domains of mental health research namely (i) mental health burden and relationship to pediatric RMD, (ii) impact of mental health disorders on outcomes, (iii) mental health awareness and education, (iv) mental health screening, and (v) mental health treatment. ${ }^{19}$ Of these, (i) and (ii) were rated as the most important and (iv) as the most feasible and actionable. ${ }^{19}$ Box 1 summarizes the key messages from this current review.

Understanding the connections between physical and mental health in CYP becomes increasingly complicated with a lack of high-powered studies, scoring systems using parentproxy measures and little understanding about the mechanics of physical-mental comorbidity in young people. ${ }^{12}$ Studies such as the prospective Canadian MYLIFE study will be particularly informative in this regard. ${ }^{114}$

The evidence continues to sadly suggest that there remains a gap which still needs to be bridged between mental and physical health, never mind between pediatric and adult rheumatology. In future national and international standards for care and training curricula, mental health needs of young people with RMD will require greater prominence in order to improve service provision and workforce competency in this area. Furthermore, adoption of a life course approach to health research will enable consideration of mental health at the potentially vulnerable times of transition during adolescence and young adulthood-pubertal, social, educational, vocational as well as health-related transitions - as all have significant implications to health.

\section{Abbreviations}

RMD, rheumatic musculoskeletal disease; JIA, juvenile idiopathic arthritis; SLE, systemic lupus erythematosus; CYP, children and young people; AYA, adolescents and young adults; SLEDAI, SLE disease activity index; SLICC, Systemic Lupus International Collaborating Clinics; EULAR, European League Against Rheumatism; PReS, Paediatric Rheumatology European Society; HEEADSSS, Home, Education/Employment, Eating, Activities, Drugs, Sexuality, Suicidal ideation and Safety; SDQ, The Strengths and Difficulties Questionnaire; PROM, patient-reported outcome; TRAQ, Transition Readiness Questionnaire; CARRA, Childhood Arthritis and Rheumatology Research Alliance; MDT, multidisciplinary team; CBT, cognitive behavioral therapy.

\section{Ethics Approval and Informed Consent}

Not applicable.

\section{Author Contributions}

All authors made substantial contributions to conception and design, acquisition of data, or analysis and interpretation of data; took part in drafting the article or revising it critically for important intellectual content; agreed to submit to the current journal; gave final approval of the version to be published; and agree to be accountable for all aspects of the work.

\section{Funding}

$\mathrm{JMcD}$ is supported by Versus Arthritis Centre for Epidemiology (UK grant No: 21755) and the NIHR Manchester Biomedical Research Centre.

\section{Disclosure}

The authors report no conflicts of interest in this work. 


\section{References}

1. Kessler RC, Berglund P, Demler O, Jin R, Merikangas KR, Walters E. Lifetime prevalence and age-of-onset distributions of DSM-IV disorder in the National comorbidity survey replication. Arch Gen Psychiatry. 2005;62(6):593-602. doi:10.1001/ archpsyc.62.6.593

2. Sadler K, Vizard T, Ford T, Goodman A, Goodman R, McManus S. Mental Health of Children and Young People in England: Trends and Characteristics. Leeds, UK: NHS Digital; 2017.

3. Mojtabai R, Olfson M, Han B. National trends in the prevalence and treatment of depression in adolescents and young adults. Pediatrics. 2006;138(6).

4. Hiscock H, Neely RJ, Lei S, et al. Paediatric mental and physical health presentations to emergency departments, Victoria, 2008-15. Med J Aust. 2018;208(8):343-348. doi:10.5694/ mja17.00434

5. Shanahan L, Steinhoff A, Bechtiger L, et al. Emotional distress in young adults during the COVID-19 pandemic: evidence of risk and resilience from a longitudinal cohort study. Psychol Med. 2020;1-32. doi:10.1017/S003329172000241X

6. Reaume SV, Ferro MA. Chronicity of mental comorbidity in children with new-onset physical illness. Child Care Health Dev. 2019;45(4):559-567.

7. Butler A, Van Lieshout RJ, Lipman EL, et al. Mental disorder in children with physical conditions: a pilot study. BMJ Open. 2018;8(1):e019011.

8. Bennett SD, Heyman I, Coughtrey AE, et al. Assessing feasibility of routine identification tools for mental health disorder in neurology clinics. Arch Dis Child. 2019;104:1161-1166. doi:10.1136/ archdischild-2018-316595

9. Hysing M, Elgen I, Gillberg C, Atle S, Lundervold A. Chronic physical illness and mental health in children. Results from a large-scale population study. J Child Psyc Psychia. 2007;48 (8):785-792. doi:10.1111/j.1469-7610.2007.01755.x

10. Green H, McGinnity A, Meltzer H, Forder T, Goodman R. Mental Health of Children and Young People in Great Britain, 2004. Office for National Statistics; 2005.

11. Memari AH, Chamanara E, Ziaee V, Kordi R, Raeeskarami SR. Behavioral problems in juvenile idiopathic arthritis: a controlled study to examine the risk of psychopathology in a chronic pediatric disorder. Int J Chronic Dis. 2016;2016:5726236.

12. Ferro MA. Major depressive disorder, suicidal behaviour, bipolar disorder, and generalised anxiety disorder among emerging adults with and without chronic health conditions. Epidemiol Psychiatr Sci. 2016;25(5):462-474. doi:10.1017/S2045796015000700

13. Quliter MC, Hiraki LT, Korczak DJ. Depressive and anxiety symptom prevalence in childhood-onset systemic lupus erythematosus: a systematic review. Lupus. 2019;28:878-887. doi:10. 1177/0961203319853621

14. Fair DC, Rodriguez M, Knight AM, Rubenstein TB. Depression and anxiety in patients with juvenile idiopathic arthritis: current insights and impact on quality of life, a systematic review. Open Access Rheumatol Res Rev. 2019;11:237-252. doi:10.2147/ OARRR.S174408

15. Farre A, McDonagh JE. Transition in rheumatology: a review of the literature from the past five years. Curr Rheumatol Rep. 2019;21(10):57. doi:10.1007/s11926-019-0855-4

16. Foster HE, Minden K, Clemente D, et al. EULAR/PReS standards and recommendations for the transitional care of young people with juvenile-onset rheumatic diseases. Ann Rheum Dis. 2017;76 (4):639-646. doi:10.1136/annrheumdis-2016-210112

17. Willis E, McDonagh JE. Shifting the mindset - adolescent and young adult rheumatology in transition. Lancet Rheumatol. 2020;2(4):e236-e244. doi:10.1016/S2665-9913(19)30163-8
18. Cordingley L, Lee RR. Can we implement the new research agenda for mental health? Nat Rev Rheumatol. 2020;16 (4):191-192. doi:10.1038/s41584-020-0399-z

19. Rubinstein TB, Ogbu EA, Rodriguez M, et al. Prioritized agenda for mental health research in pediatric rheumatology from the childhood arthritis and rheumatology research alliance mental health workgroup. $J$ Rheumatol. 2020;jrheum.190361. doi:10.38 99/jrheum.190361

20. Tong A, Jones J, Craig JC, Singh-Grewal D. Children's experiences of living with juvenile idiopathic arthritis: a thematic synthesis of qualitative studies. Arthritis Care Res (Hoboken). 2012;64 (9):1392-1404. doi:10.1002/acr.21695

21. Szulczewski L, Mullins LL, Bidwell SL, Eddington AR, Pai ALH. Meta-analysis: care giver and youth uncertainty in pediatric chronic illness. $J$ Pediatr Psychol. 2016;42:395-421.

22. Hanns L, Radziszewska A, Suffield L, et al. Association of anxiety with pain and disability but not with increased measures of inflammation in adolescent patients with juvenile idiopathic arthritis. Arthritis Care Res (Hoboken). 2020;72(9):1266-1274. doi:10.1002/acr.24006

23. Castaneda AE, Tuulio-Henriksson A, Aronen ET, Marttunen M, Kolho K. Cognitive functioning and depressive symptoms in adolescents with inflammatory bowel disease. World J Gastroenterol. 2013;19(10):1611-1617. doi:10.3748/wjg.v19.i10.1611

24. Graziano S, Rossi A, Spano B, Petrocchi M, Biondi G, Ammaniti M. Comparison of psychological functioning in children and their mothers living through a life-threatening and non life-threatening chronic disease: a pilot study. J Child Health Care. 2016;20(2):174-184. doi:10.1177/1367493514563854

25. Ocakoglu BK, Karaca NE, Ocakoglu FT, Erermis S. Psychological burden of pediatric primary immunodeficiency. Pediatr Int. 2018;60:911-917. doi:10.1111/ped.13675

26. Hanns L, Cordingley L, Galloway J, et al. Depressive symptoms, pain and disability for adolescent patients with juvenile idiopathic arthritis: results from the Childhood Arthritis Prospective Study. Rheumatology (Oxford). 2018;57(8):1381-1389. doi:10.1093/ rheumatology/key088

27. El-Najjar AR, Negm MG, El-Sayed WM. The relationship between depression, disease activity and physical function in juvenile idiopathic arthritis patients in Zagazig University Hospitals - Egypt. Egypt Rheumatol. 2014;36(3):145-150. doi:10. 1016/j.ejr.2014.01.001

28. Barth S, Haas JP, Schlichtiger J, et al. Long-term health-related quality of life in German patients with juvenile idiopathic arthritis in comparison to German general population. PLoS One. 2016;11 (4):e0153267. doi:10.1371/journal.pone.0153267

29. Tarakci E, Yeldan I, Kaya Mutlu E, Baydogan SN, Kasapcopur O. The relationship between physical activity level, anxiety, depression, and functional ability in children and adolescents with juvenile idiopathic arthritis. Clin Rheumatol. 2011;30 (11):1415-1420. doi:10.1007/s10067-011-1832-0

30. Knight A, Vickery M, Fiks AG, Barg FK. The illness experience of youth with lupus/mixed connective tissue disease: a mixed methods analysis of patient and parent perspectives. Lupus. 2016;25(9):1028-1039. doi:10.1177/09612033 16646460

31. Petrongolo JL, Zelikovsky N, Keegan RM, Furth SL, Knight A. Examining uncertainty in illness in parents and children with chronic kidney disease and systemic lupus erythematosus: a mediational model of internalizing symptoms and health-related quality of life. J Clin Psychol Med Settings. 2020;27(1):31-40. doi:10.1007/s10880-019-09617-3

32. Thapar A, Collishaw S, Pine DS, Thapar A. Depression in adolescence. Lancet. 2012;379(9820):1056-1067. doi:10.1016/ S0140-6736(11)60871-4 
33. Rubenstien TB, Putterman C, Goilav B. Biomarkers for CNS involvement in pediatric lupus. Biomark Med. 2015;9(6): 545-558. doi:10.2217/bmm.15.26

34. Jones JT, Cunningham N, Kashikar-zuck S, Brunner HI. Pain, fatigue, and psychosocial impact on health related quality of life in Childhood-onset lupus. Arthritis Care Res (Hoboken). 2016;68 (1):73-80. doi:10.1002/acr.22650

35. Knight AM, Trupin L, Katz P, Yelin E, Lawson EF. Depression risk in young adults with juvenile- and adult-onset lupus: twelve years of followup. Arthritis Care Res. 2018;70:475-480.

36. Tobias J, Deere K, Clinch J, Clark EM, Clinch J. Hypermobility and mechanical pain. Arthritis Rheum. 2013;65(4):1107-1115. doi:10.1002/art.37836

37. Szulczewski L, Mullins LL, Bidwell SL, Eddington AR, Pai ALH. Meta-analysis: caregiver and youth uncertainty in pediatric chronic illness. J Pediatr Psychol. 2017;42 (4):395-421. doi:10.1093/jpepsy/jsw097

38. Pincus T, Noel M, Jordan A, Serbic D. Perceived diagnostic uncertainty in pediatric chronic pain. Pain. 2018;159:1198-1201.

39. Jastrowski Mano KE, O’Bryan EM, Gibler RC, Beckmann E. The co-occurrence of pediatric chronic pain and anxiety: a theoretical review of a developmentally informed shared vulnerability model. Clin J Pain. 2019;35(12):989-1002. doi:10.1097/AJP.00 00000000000763

40. Caes L, Fisher E, Clinch J, Eccleston C. Current evidence-based interdisciplinary treatment options for pediatric musculoskeletal pain. Curr Treat Opt Rheumatol. 2018;4(3):223-234. doi:10.10 07/s40674-018-0101-7

41. Soltani S, Kopala-Sibley DC, Noel M. The co-occurrence of pediatric chronic pain and depression: a narrative review and conceptualization of mutual maintenance. Clin J Pain. 2019;35 (7):633-643. doi:10.1097/AJP.0000000000000723

42. Kyvsgaard N, Thastum M, Mikkelsen TS, Christensen AE, Herlin T. Coping strategies and anxiety in association with methotrexate-induced nausea in juvenile idiopathic arthritis. Rheumatol Int. 2020;40(4):591-598. doi:10.1007/s00296-02004520-9

43. Mulligan K, Wedderburn LR, Newman S. The experience of taking methotrexate for juvenile idiopathic arthritis: results of a cross-sectional survey with children and young people. Pediatr Rheumatol Online J. 2015;13:58. doi:10.1186/s12969-015-0052-6

44. Elitsur R, Hollenbeck A, Tasan L, et al. Efficacy and cost savings with the use of a minimal sedation/anxiolysis protocol for intra-articular corticosteroid injections in children with juvenile idiopathic arthritis: a retrospective review of prospectively collected data. Pediatr Rheumatol Online J. 2019;17(1):11 doi:10.1186/s12969-019-0312-y

45. Weiss JE, Uribe AG, Malleson PN, Kimura Y. Anesthesia for intra-articular corticosteroid injections in juvenile idiopathic arthritis. Pediatr Rheumatol Online J. 2010;8:3. doi:10.1186/ 1546-0096-8-3

46. Casado R, Lumbreras J, de Inocencio J, Remesal A, Merino R, García-Consuegra J. Sedation for intra-articular corticosteroid injections in juvenile idiopathic arthritis: the views of patients and their parents. Eur J Pediatr. 2013;172(10):1411-1413. doi:10.1007/s00431-013-2052-1

47. Sørensen K, Skirbekk H, Kvarstein G, Wøien H. Children's fear of needle injections: a qualitative study of training sessions for children with rheumatic diseases before home administration. Pediatr Rheumatol Online J. 2020;18(1):13

48. Waite-Jones JM, Swallow V, Madill A. From 'neurotic' to 'managing' mother: the 'medical career' experienced by mothers of a child diagnosed with juvenile idiopathic arthritis. $\mathrm{Br} J$ Health Psychol. 2020;25(2):324-338. doi:10.1111/bjhp.12409
49. Zeng F, Xu Q, Liu D, et al. Relatives' quality of life and psychological disturbance: a new concern of SLE management. Clin Rheumatol. 2018;37(1):67-73. doi:10.1007/s10067-017-3743-1

50. van Oers HA, Haverman L, Limperg PF, van Dijk-lokkart EM, Maurice-Stam H, Grootenhuis MA. Anxiety and depression in mothers and fathers of a chronically ill child. Matern Child Health J. 2014;18(8):1993-2002. doi:10.1007/s10995-0141445-8

51. Selvaag AM, Aulie HA, Lilleby V, Flatø B. Disease progression into adulthood and predictors of long-term active disease in juvenile idiopathic arthritis. Ann Rheum Dis. 2016;75(1): 190-195. doi:10.1136/annrheumdis-2014-206034

52. Raab A, Sengler C, Niewerth M, et al. Comorbidity profiles among adult patients with juvenile idiopathic arthritis: results of a biologic register. Clin Exp Rheumatol. 2013;31(5):796-802.

53. Rebane K, Ristolainen L, Relas H, et al. Disability and health-related quality of life are associated with restricted social participation in young adults with juvenile idiopathic arthritis. Scand J Rheumatol. 2019;48(2):105-113. doi:10.1080/030097 42.2018.1493140

54. Raafat HA, El Refai RM, Alrasheed HA, El Din MN. Major depression and disease activity among systemic lupus erythematosus Egyptian females. Egypt Rheumatol. 2015;37(4):S1-S6. doi:10.1016/j.ejr.2015.09.007

55. Zakeri Z, Shakiba M, Narouie B, Mladkova N, Ghasemi-Rad M, Khosravi A. Prevalence of depression and depressive symptoms in patients with systemic lupus erythematosus: Iranian experience. Rheumatol Int. 2012;32(5):1179-1187. doi:10.1007/ s00296-010-1791-9

56. Zhang L, Fu T, Yin R, Zhang Q, Shen B. Prevalence of depression and anxiety in systemic lupus erythematosus: a systematic review and meta-analysis. BMC Psychiatry. 2017;17(1):70. doi:10.1186/s12888-017-1234-1

57. Phuti A, Schneider M, Tikly M, et al. Living with systemic lupus erythematosus in the developing world. Rheumatol Int. 2018;38:1601-1613. doi:10.1007/s00296-018-4017-1

58. Son MB, Sergeyenko Y, Guan H, Costenbader KH. Disease activity and transition outcomes in a childhood-onset systemic lupus erythematosus cohort. Lupus. 2016;25(13):1431-1439. doi: $10.1177 / 0961203316640913$

59. Colver A, McConachie H, Le Couteur A, et al. A longitudinal, observational study of the features of transitional healthcare associated with better outcomes for young people with long-term conditions. BMC Med. 2018;16(1):111. doi:10.1186/s12916-018-1102-y

60. Doukrou M, Segal TY. Fifteen-minute consultation: communicating with young people -how to use HEEADSSS, a psychosocial interview for adolescents. Arch Dis Child Educ Pract Ed. 2018;103:15-19. doi:10.1136/archdischild-2016-311553

61. Hislop J, Mason H, Parr JR, Vale L, Colver A. Views of young people with chronic conditions on transition from pediatric to adult health services. J Adolesc Health. 2016;59(3):345-353. doi:10.1016/j.jadohealth.2016.04.004

62. MacDonald AJD, Fugard AJB. Routine mental health outcome measurement in the UK. Int Rev Psychiatr. 2015;27(4):306-319. doi:10.3109/09540261.2015.1015505

63. Shaffer D, Gould MS, Brasic J, et al. A Children's Global Assessment Scale (CGAS). Arch Gen Psychiatry. 1983;40 (11):1228-1231. doi:10.1001/archpsyc.1983.01790100074010

64. Goodman R. the strengths and difficulties questionnaire: a research note. $J$ Child Psychol Psychiatry. 1997;38 (5):581-586. doi:10.1111/j.1469-7610.1997.tb01545.x

65. Gowers SG, Harrington RC, Whitton A, et al. A Brief Scale for measuring the outcomes of emotional and behavioural disorders in children: hoNOSCA. Br J Psychiatr. 1999;174:413-416. doi:10.1192/bjp.174.5.413 
66. Stinson J, Kohut SA, Spiegel L, et al. A systematic review of transition readiness and transfer satisfaction measures for adolescents with chronic illness. Int J Adolesc Med Health. 2014;26 (2):159-174. doi:10.1515/ijamh-2013-0512

67. Akre C, Suris JC, Belot A, et al. Building a transitional care checklist in rheumatology: a Delphi-like survey. Joint Bone Spine. 2018;85(4):435-440\#. doi:10.1016/j.jbspin.2017.09.003

68. McDonagh JE, Hackett J, McGee M, Southwood T, Shaw KL. The evidence base for transition is bigger than you might think. Arch Dis Child Educ Pract Ed. 2015;100(6):321-322. doi:10.11 36/archdischild-2015-309204

69. Walter M, Kamphuis S, van Pelt P, de Vroed A, Hazes JMW. Successful implementation of a clinical transition pathway for adolescents with juvenile-onset rheumatic and musculoskeletal diseases. Pediatr Rheumatol. 2018;16:50. doi:10.1186/s12969018-0268-3

70. Nagra A, McGinnity PM, Davis N, Salmon AP. Implementing transition: ready steady go. Arch Dis Child Educ Pract Ed. 2015;100(6):313-320. doi:10.1136/archdischild-2014-307423

71. Wood DL, Sawicki GS, Miller MD, et al. The Transition Readiness Assessment Questionnaire (TRAQ): its factor structure, reliability, and validity. Acad Pediatr. 2014;14:415-422. doi:10.1016/j.acap.2014.03.008

72. Moynihan M, Saewyc E, Whitehouse S, Paone M, McPherson G. Assessing readiness for transition from paediatric to adult healthcare: revision and psychometric evaluation of the Am I ONTRAC for adult care questionnaire. J Adv Nurs. 2015;71:1324-1335. doi:10.1111/jan.12617

73. Ferris ME, Harward D, Bickford K, et al. The development of the UNC TRxANSITION scale: a clinical tool to measure the components of health care transition. Ren Fail. 2012;34(6):744-753. doi:10.3109/0886022X.2012.678171

74. Zhong Y, Gilleskie DB, van Tilburg MAL, et al. Longitudinal self-management and/or transition readiness per the TR $x$ ANSITION index among patients with chronic conditions in pediatric or adult care settings. J Pediatr. 2018;203:361-370.e1. doi:10.1016/j.jpeds.2018.06.052

75. Lugasi T, Achille M, Stevenson M. Patients' perspective on factors that facilitate transition from child-centred to adultcentred health care: a theory integrated metasummary of quantitative and qualitative studies. J Adol Health. 2011;48:429-440. doi:10.1016/j.jadohealth.2010.10.016

76. Gray WN, Schaefer MR, Resmini-Rawlinson A, Wagoner ST. Barriers to transition from pediatric to adult care: a systemic review. J Pediatr Psychol. 2018;43(5):488-502. doi:10.1093/jpepsy/jsx142

77. Felsentein S, Reiff AO, Ramanathan A. Transition of care and health-related outcomes in pediatric-onset systemic lupus erythematosus. Arthritis Care Res (Hoboken). 2015;67(11):15 21-1528. doi:10.1002/acr.22611

78. Broad KL, Sandhu VK, Sunderji N, Charach A. Youth experiences of transition from child mental health services to adult mental health services: a qualitative thematic synthesis. $B M C$ Psychiatry. 2017;17:380. doi:10.1186/s12888-017-1538-1

79. Singh SP, Paul M, Ford T, et al. Process, outcome and experience of transition from child to adult mental healthcare: multiperspective study. Br J Psychiatry. 2010;197:305-312. doi:10.1192/bjp. bp.109.075135

80. Hendrickx G, De Roeck V, Maras A, et al. Challenged during the transition from child to adolescent mental health services to adult mental health services. BJPsych Bull. 2020. doi:10.1192/bjb.2019.85

81. Santosh P, Singh J, Adams L; The MILESTONE Consortium, et al. Validation of the Transition Readiness and Appropriateness Measure (TRAM) for the Managing the Link and Strengthening Transition from Child to Adult Mental Healthcare in Europe (MILESTONE) study. BMJ Open. 2020;10:e033324. doi:10.11 36/bmjopen-2019-033324
82. Ramos AL, Hoffmann F, Albrecht K, Klotsche J, Zink A, Minden K. Transition to adult rheumatology care is necessary to maintain DMARD therapy in young people with juvenile idiopathic arthritis. Semin Arthritis Rheum. 2017;47:269-275. doi:10.1016/j.semarthrit.2017.05.003

83. Kieckhefer GM, Trahms CM. Supporting development of children with chronic condi6tions: from compliance toward shared management. Pediatr Nurs. 2000;26:354-363.

84. Annunziato RA, Arrato N, Rubers M, Arnon R. The importance of mental health monitoring during transfer to adult care settings as examined among paediatric transplant recipients. J Paed Child Health. 2015;51:220-222. doi:10.1111/jpc.12765

85. Zheng K, Abraham C, Bruzzese JM, Smaldone A. Longitudinal relationships between depression and chronic illness in adolescents: an integrative review. J Pediatr Health Care. 2020;S08915245(19)30660-1. doi:10.1016/j.pedhc.2020.01.008

86. Spear LP. The adolescent brain and age-related behavioral manifestations. Neurosci Behav Rev. 2000;24:417-463. doi:10.10 16/S0149-7634(00)00014-2

87. Herting MM, Sowell ER. Puberty and structural brain development in humans. Front Neuroendocrinol. 2017;44:122-137. doi:10.1016/j.yfrne.2016.12.003

88. Gruttadaro D, Crudo D College students speak: a survey report on mental health. National alliance on mental illness; 2012. Available from: https://www.nami.org/Support-Education /Publications-Reports/Survey-Reports/College-Students-Speak_A -Survey-Report-on-Mental-H. Accessed November 6, 2020.

89. Hage A, Weymann L, Bliznak L, Marke V, Mechler K, Dittmann RW. Non-adherence to psychotropic medication among adolescents - a systematic review of the literature. Zeitschrift für Kinder- und Jugendpsychiatrie und Psychotherapie. 2018;46(1):69-78.

90. Groenewald CB, Giles M, Palermo TM. School absence associated with childhood pain in the United States. Clin J Pain. 2019;35(6):525-531. doi:10.1097/AJP.0000000000000701

91. Tran S, Jastrowski Mano KE, Anderson Khan K, Davies WH, Hainsworth KR. Patterns of anxiety symptoms in pediatric chronic pain as reported by youth, mothers, and fathers. Clin Paract Pediatr Psychol. 2016;4(1):51-62. doi:10.1037/cpp0000126

92. Hanns L, Radziszewska A, Suffield L, et al. Anxiety associates with pain and disability but not increased measures of inflammation for adolescent patients with juvenile idiopathic arthritis. Arthritis Care Res (Hoboken). 2019. doi:10.1002/ acr. 24006

93. Knight AM, Vickery ME, Fiks AG, Barg FK. Barriers and facilitators for mental healthcare in pediatric lupus and mixed connective tissue disease: a qualitative study of youth and parent perspectives. Pediatr Rheumatol Online J. 2015;13:52. doi:10.11 86/s12969-015-0049-1

94. Knight AM, Vickery ME, Muscal E, et al. Identifying targets for improving mental healthcare of adolescents with systemic lupus erythematosus: perspectives from pediatric rheumatology clinicians in the United states and Canada. J Rheumatol. 2016;43: 1136-1145. doi:10.3899/jrheum. 151228

95. Knight A, Vickery M, Faust L, et al. Gaps in mental health care for youth with rheumatologic conditions: a mixed methods study of perspectives from behavioral health providers. Arthritis Care Res (Hoboken). 2019;71(5):591-601. doi:10.1002/acr.23683

96. Smith E, Willis E, McDonagh JE. Adolescent and young adult health training needs of health professionals including rheumatology. Rheumatology. 2019;58(supp3). doi:10.1093/rheumatology/kez416

97. Young Persons Health Special Interest Group. The YPHSIG APP. Available from: https://www.yphsig.org.uk/resources-1/app. Accessed November 6, 2020. 
98. Thabrew H, Goodyear-Smith F. Youth version, Case-finding and Help Assessment Tool (YouthCHAT): an electronic, psychosocial screener for young people with long-term physical conditions. J Paediatr Child Health. 2019. doi:10.1111/jpc.14503

99. Hawley DP, Howsley P, McDonagh JE, et al. United Kingdom survey of access to psychology services for adolescents and young adults with rheumatic and musculoskeletal disease. Rheumatology. 2018;8:P24.

100. Signorini G, Singh SP, Boricevic-Marsanic V, et al. Architecture and functioning of child and adolescent mental health services: a 28-country survey in Europe. Lancet Psychiatr. 2017;4(9):7 15-724. doi:10.1016/S2215-0366(17)30127-X

101. Smith J, Kyle RG, Daniel B, Hubbard G. Patterns of referral and waiting times for specialist child and adolescent mental health services. Child Adolesc Ment Health. 2018;23(1):41-49. doi:10. 1111/camh.12207

102. Davis AM, Rubinstein TB, Rodriguez M, Knight AM. Mental health care for youth with rheumatologic diseases - bridging the gap. Pediatr Rheumatol. 2017;15:85. doi:10.1186/s12969-0170214-9

103. Thabrew H, Stasiak K, Hetrick SE, Wong S, Huss JH, Merry SN. E-Health interventions for anxiety and depression in children and adolescents with long-term physical conditions. Cochrane Database Syst Rev. 2018;8:CD012489.

104. Thabrew H, Stasiak K, Hetrick SE, et al. Psychological therapies for anxiety and depression in children and adolescents with long-term physical conditions. Cochrane Database Syst Rev. 2018;12(12):CD012488.

105. Cunningham NR, Fusner LM, Moorman E, Avar Aydin PO, Kashikar-Zuch S, Kashikar-Zuck S. Development and pilot testing of the treatment and education approach for childhood-onset lupus (TEACH): a cognitive behavioural treatment. Paed Rheum Online J. 2019;17:9. doi:10.1186/s12969-019-0307-8

106. Glazebrook C, Hollis C, Heussler H, Goodman R, Coates L. Detecting emotional and behavioural problems in paediatric clinics. Child Care Health Dev. 2003;29(2):141-149. doi:10.10 46/j.1365-2214.2003.00324.x
107. Hinrichs S, Owens M, Dunn V, Goodyer I. General practitioner experience and perception of Child and Adolescent Mental Health Services (CAMHS) care pathways: a multimethod research study. BMJ Open. 2012;2(6):e001573. doi:10.1136/bmjopen-2012-001 573

108. Wright RJ, Howard EJ, Newbery N, Gleeson H. Training gap the present state of higher specialty training in adolescent and young adult health in medical specialties in the UK. Future Healthc J. 2017;4:80-85.

109. Cooper S, Valleley RJ, Polaha J, Begeny J, Evans JH. Running out of time: physician management of behavioral health concerns in rural pediatric primary care. Pediatrics. 2006;118(1):e132-8. doi:10.1542/peds.2005-2612

110. Meadows T, Valleley R, Haack MK, Thorson R, Evans J. Physician "costs" in providing behavioral health in primary care. Clin Pediatr (Phila). 2011;50(5):447-455. doi:10.1177/ 0009922810390676

111. Farre A, Wood V, McDonagh JE, et al. Health professionals' and managers' definitions of developmentally appropriate healthcare for young people: conceptual dimensions and embedded controversies. Arch Dis Child. 2016;101(7):628-633. doi:10.1136/archdischild-2015-309473

112. Ambresin AE, Bennett K, Patton GC, Sanci LA, Sawyer SM. Assessment of youth-friendly health care: a systematic review of indicators drawn from young people's perspectives. J Adolesc Health. 2013;52(6):670-681. doi:10.1016/j.jadohealth.2012.12. 014

113. Cai RA, Chaplin H, Livermore P, et al. Development of a benchmarking toolkit for adolescent and young adult rheumatology services (BeTAR). Pediatr Rheumatol Online J. 2019;17 (1):23. doi:10.1186/s12969-019-0323-8

114. Ferro MA, Lipman EL, Van Lieshout RJ, et al. Multimorbidity in Children and Youth Across the Life-course (MY LIFE): protocol of a Canadian prospective study. BMJ Open. 2019;9(11):e034544. doi:10.1136/bmjopen-2019-034544

\section{Publish your work in this journal}

Open Access Rheumatology Research and Reviews is an international, peer-reviewed, open access journal publishing original research, reports, editorials, reviews and commentaries on all aspects of clinical and experimental rheumatology in the clinic and laboratory including the following topics: Pathology, pathophysiology of rheumatological diseases; Investigation, treatment and management of rheumatological diseases; Clinical trials and novel pharmacological approaches for the treatment of rheumatological disorders. The manuscript management system is completely online and includes a very quick and fair peer-review system, which is all easy to use. Visit http://www.dovepress.com/testimonials.php to read real quotes from published authors. 